Théologiques

Théologiques

\title{
The Cosmos and Theological Reflection: The Priority of Self-Transcendence
}

\section{Paul Allen}

Volume 9, numéro 1, printemps 2001

Les cosmologies

URI : https://id.erudit.org/iderudit/005683ar

DOI : https://doi.org/10.7202/005683ar

Aller au sommaire du numéro

\section{Éditeur(s)}

Faculté de théologie de l'Université de Montréal

ISSN

1188-7109 (imprimé)

1492-1413 (numérique)

Découvrir la revue

Citer cet article

Allen, P. (2001). The Cosmos and Theological Reflection: The Priority of Self-Transcendence. Théologiques, 9(1), 71-93. https://doi.org/10.7202/005683ar
Résumé de l'article

Dans cet article, je suggère que la signification première de la cosmologie pour la théologie passe par la notion d'auto-transcendance. C'est une notion foncièrement théologique qui émerge dans la cosmologie. Elle pointe vers le domaine de l'intériorité mis de l'avant par la théologie contemporaine. A partir, en particulier, de la pensée d'Ernan McMullin, j'affirme que l'auto-transcendance émerge d'une recherche cosmologique quand elle devient philosophie et comporte une extrapolation. Une ouverture théologique envers la cosmologie est justifiée quand on en saisit les limites en tant que discipline empirique au cœur des questions existentielles possibles sur le sens de l'univers ; un déplacement qui est bien illustré par le principe anthropique. 


\title{
The Cosmos and Theological Reflection:
}

The Priority of Self-Transcendence

\author{
Paul ALLEN \\ Université Saint-Paul \\ Ottawa
}

"The cosmos is all that is or ever was or ever will be.

Our feeblest contemplations of the Cosmos stir us...

[w]e know we are approaching the greatest of mysteries."

In the work of recent Christian theologians, key shifts in language and cultural meaning have impacted the way theological claims are made in relation to the universe as a cosmic reality. As a result, theological meaning has drifted decisively toward the domain of interiority and away from objectivizing metaphysical claims. Theology has moved away from "approaching the greatest of mysteries" as Carl Sagan calls cosmological study in the above quote. Thus, until recently there has been relatively little theological analysis or critique directed toward such claims that the universe is all there is.

So, the recent exchanges between the natural sciences and theology over the past two decades comes as an intellectual shock for those whose habits of thought assumed a reigning consensus against interdisciplinary reflection and theological metaphysics. Far from being an exceptional instance of esoteric ideology, the dialogue between the natural sciences and religious or theological traditions has blossomed. Along the way, this dialogue has attracted the sustained attention of respected philosophers and scientists, as well as a few theologians.

This dialogue gained momentum, at least in the English-speaking world, with public musings by practising scientists concerning an alleged connection between science and religion. Such figures include noted British physicist John Polkinghorne and the American astrono- 
mer Owen Gingerich. The question is: can such scientific forays into the religious domain be sustained into the next century? For now, the most likely incentive for extending the science-theology dialogue might be due to the ethical impulse.

Bioethical, biotechnological and ecological discussions are intensifying along the theoretical terrain. The twenty-first century will see an escalation of theoretical questions, likely around the core question of human identity. What is our real nature? The question of our ultimate destiny transcends the ability of ethical inquiries to resolve foundational questions. Theologians will need to engage the question of human destiny with practitioners in three scientific disciplines: the neurosciences, evolutionary biology and astrophysical cosmology. While the neurosciences push the mind-body problem very deep, the investigations of evolutionary biologists touch on similar themes from the point of view of our origins as a species. Cosmology, however, possesses a unique status in connecting scientific inquiry with theological reflection. Unique among scientific disciplines, cosmology conveys a radical sense of the limits of science in the face of contingency. In spite of all the advances that have been made, contemporary cosmology cannot satisfactorily answer the question: "Why is there something rather than nothing?" Theologically speaking, cosmology faces the limit of an affirmation of our being created by God, of creation as an affirmation of pure gift.

In assessing the unique stature of cosmology, it bears repeating at the outset that theologians should not feel obliged to position themselves as philosophers of religion. In this paper, I will argue that the notion of self-transcendence is an inherently theological notion. Moreover, it is a theologically pregnant experience of self-knowledge that arises in cosmology itself. Employing the thought of several thinkers, notably Ernan McMullin, I claim that self-transcendence emerges within cosmological inquiry due to a form of creative extrapolation that is involved. A theological thrust to cosmology is confirmed when one understands the limits of cosmology as an empirical discipline amidst the existential questions that can be posed about the meaning of the universe. The so-called anthropic principle illustrates this step very well. Some brief conclusions on theological method are made at the end of the paper. 


\section{Interpreting Cosmology as Self-Transcendence}

The historical variety of theological interpretations of the universe ranges from the employment of neo-Aristotelian metaphysics to the Ptolemaic system of crystalline orbs claimed as surrounding earth. This plurality of theological worldviews attests to the ways in which a teleological account of the universe was sustained according to the differentiated patterns of meaning in different cultures ${ }^{1}$. Without a doubt, this variety of scientific and cultural contexts that informed the history of systematic theological appropriation of cosmology cannot be ignored.

Nevertheless, if theologians want to claim a relationship between the cosmos and a living God, they are obliged to ensure that their claims are not scientifically incoherent. Theologians need to beware the possibility of their claims being undermined by natural scientists ${ }^{2}$. Of all the natural sciences, cosmology potentially has the most to offer contemporary philosophy and theology, especially in light of its recent ascendance as a discipline from near obscurity at the turn of this century, when it was even disallowed scientific and learned status ${ }^{3}$. Serious hurdles remain in the attempt to interpret cosmology authentically. It is already evident that interpretations in support of theological claims concerning God are vulnerable to forms of theological

1. For an insightful overview of the question, see Jean LADRIERE's "Faith and Cosmology" in Language and Belief, Notre Dame IN, University of Notre Dame Press, 1984, p. 149-86 and Noriss Hetherington, ed., Cosmology: Historical, Literary, Philosophical, Religious and Scientific Perspectives, New York \& London, Garland, 1993.

2. Recall the quote from Ralph Waldo EMERSON that "the religion that fears science insults God and commits suicide." Quoted in Max JAMMER, Einstein and Religion, Physics and Theology, Princeton, NJ, Princeton University Press, 1999, p. 155.

3. See a book review by Dick TeRESI in the New York Times, in which he cites a revealing anecdote: "In 1966, when the cosmologist Edward Harrison accepted a teaching post at the University of Massachusetts, he was handed the Redbook, a manual for faculty members that explained what a university was, and what it wasn't. It cited two courses one wouldn't find in a curriculum of higher education: witchcraft and cosmology." This August, 1999 review has been available at the following URL: <http://www.nytimes.com/ books/99/08/08/reviews/990808.08teresit.html>. 
positivism. After all, it is true that motives for belief, at least in Christian theology, have not been primarily cosmological. Theological interpretations of cosmology are also vulnerable to epistemological and hermeneutical suspicions as well. It would therefore be ill advised for theologians to engage cosmology simply by employing metaphysical arguments. It would be an error of judgment to think that theology be granted cosmological carte blanche on the supposition that cosmological discoveries such as "Big Bang" theories of universal origins or anthropic cosmological principles permit free theological speculation.

Since the discovery of universal relativity theories, the cosmic space-time continuum has been accorded intelligibility as a singular object. Its emergence as a science has been the result of specific discoveries, such as the discovery by Penzias and Wilson in 1965 of the Cosmic Microwave Background Radiation, which largely confirmed the Big Bang Theory of universal origins. This discovery, among others, thrust cosmology back from its prior irrelevance as a branch of the philosophy of nature, traditionally dominated by forms of idealism. The direct confirmation of the 'Big Bang' theory of universal origins, with its' accent on a temporal beginning of time, led to immediate associations with biblical and other religious cosmogonies.

Nevertheless, it is with some reason that some thinkers within the science-theology dialogue insist on the need to curtail metaphysical discourse. Mary Hesse, for instance, comments:

“...science-based models....are metaphors for God, not metaphysics. Nevertheless metaphors and analogies are not to be devalued; they and not metaphysics are in the end the only way we can speak about God, and indeed also of natural reality. Metaphors do not exclude belief in God's existence, although they cannot totally represent him. Metaphors may be better or worse, and appropriate metaphors may even come from natural science itself, but the criteria of appropriateness must arise chiefly from domains of human life, history and society that transcend science ${ }^{4}$."

Note that Hesse still accepts the validity of arguing from nature to God, except without explanatory intent. Nevertheless, contra Hesse, a closer attention to contemporary cosmology may still profitably yield a

4. See Mary HESSE, "The sources of models of God: metaphysics or metaphor?", in Jan Hilgevoord, ed. Physics and Our View of the World, Cambridge, Cambridge University Press, 1994, p. 252-53. 
limited metaphysical view of the universe. The key lies in approaching the subject of cosmology from the horizon of inquiry itself. ${ }^{5}$

It is true that theoretical astrophysics will rapidly progress during the next century. As a result, such important theories as the anthropic principle and Big Bang theories of universal origins could be replaced or severely constrained. So, there is a danger to thinking that particular cosmological theory, past, present or future, is required to affirm a relationship between the universe and God. But, a Christian or tradition-bound cosmology is not the result of an inference directly derived from cosmology to theology ${ }^{6}$. Theological reflections of this sort generally derive from the need to communicate the meaning of some kind of doctrinal theological position or belief. It is instructive that Albert Einstein, the greatest scientist of the twentieth century, did not pursue this line of thinking in terms of his own religious beliefs. According to Max Jammer, Einstein "never based his religion on logical inferences from his scientific work ${ }^{7}$. (Jammer, 1999, p. 11)" His

5. The most theologically adequate metaphysical position has been worked out by Bernard LONERGAN. See L'insight : étude de la comprébension humaine traduit de l'anglais par Pierrot Lambert, Montréal, Bellarmin, 1996, especially chapters 14-17 where metaphysics is understood to function as an "integral heuristic structure of proportionate being." An inquiry-based metaphysic avoids the traps of rigid empiricism and idealism.

6. For an example of this kind of theological argument, see Duane LARSON, Times of the Trinity: A Proposal for a Theistic Cosmology, New York, Peter Lang, 1996 where the trinitarian nature of God is defended with reference to cosmology's findings primarily on the basis of an appraisal of discoveries about time and eternity. In this work, as with others, insufficient attention has been paid to the role of language and analogy. An underlying reason for resisting an overt theological cosmology is based on a historical reading of theology's demise during the scientific revolution. Michael Buckley's At the Origins of Modern Atheism, New Haven, Yale University Press, 1987 masterfully details this dramatic turn of events. Citing the influence of early modern figures such as Leonard Lessius and Marin Mersenne, Buckley shows how the turn away from christology toward the nature of proportionate space and time in natural theology set the stage for the onset of atheism. He shows how theologians gave up on religion and religious experience at a key moment in western intellectual history.

7. JAMMER, op cit, $p .11$ 
religious inclinations were rather an expression of hope against the "vanity of human rivalry in the struggle for existence... ${ }^{8}$

This cautionary note on drawing inferences from the cosmos to God does not negate the possibility of more modest theological metaphysics. However, it does alert theologians to the significance of error, exemplified in events such as the Galileo affair as well as less serious incidents. For example, Pius XII's hasty 1951 endorsement of Big Bang cosmology for its confirmation of Genesis creation narratives would be such an instance of theological impatience with cosmology. Such incidents show that a more reflective position is called for.

I want to assist constructing an alternative by referring to a critical distinction offered by the philosopher of cosmology, Milton Munitz:

"The need to have a cosmology, an acceptable picture of the universe generally derives from two principal motives. One is curiosity, a purely intellectual craving and sense of wonder that prompts the asking of certain questions [...] These are questions about the temporal, spatial, compositional, teleologic properties of the universe [...] A second motive underlying the search for a satisfying cosmology derives from the human need to "situate" the life of human beings in the universe [...] The combination of these two motives has been the principal sustaining incentive in the pursuit of cosmology ${ }^{9}$."

The distinction Munitz draws between an intellectual or scientific cosmological inquiry on the one hand, and an existential or interpretive inquiry on the other hand, is extremely helpful. It is an important distinction for theologians to keep in mind when appropriating cosmological data.

Obviously, a metaphysical theology that excludes an existential interpretation of cosmology is self-defeating. Theologians are well aware, since the rise of postmodern thought, of the need to communicate in terms of human historicity and meaning. Yet, there are two powerful reasons to think of empirical and existential cosmology as linked undertakings. In making this case, William Stoeger states:

8. Ibid., p. 20

9. Milton Munitz, Cosmic Understanding: Philosophy and Science of the Universe, Princeton, Princeton University Press, 1986, p. 5-6. 
"Cosmology — in the areas of physics it embraces - does deal with many of the fundamental characteristics of physical reality in general, space and time, matter (mass-energy) and its transformations, causality and its physical roots, in a way which sometimes reminds us of philosophy...[L]ike other scientific disciplines, it examines particulars and their relationships and interactions in a dialectic of theory and experiment/observation. It is just that in this case these particulars pertain to some of the most general and universal features of physical reality; the focus is on these structures and particulars with the aim of uncovering their significance and relevance for the larger whole, the observable universe ${ }^{10}$."

That is, whether or not cosmic intelligibility is expressed in prominent theories like the anthropic principle, it is inquiry that points to the ultimate limits of any inquiry into the universe.

For Munitz, who, unlike Stoeger, is not an explicit theist, the implication of cosmic intelligibility is its inherent limitation. It is limited by what he terms "the Boundless." He defines this as "neither observable, intelligible, nor known ${ }^{11}$. (Munitz, 1986, p. 184)" In relation to the natural universe, the Boundless is a concept that he differentiates from both theism and a Spinozistic unity of God and nature. What is questionable perhaps is the issue of whether human history and meaning possess an intelligibility that interrupts, to a certain extent, this more straightforward notion of transcendence. In fact, given the questions of human identity and destiny that emerge in cosmology, I would claim that human historicity does possess an intelligibility, to the extent that it arises from self-transcendence.

Before skipping ahead too far, there is a second key insight into contemporary cosmology that should be underlined. This is cosmology's inherent relationship to philosophy, according to Stoeger:

"[...] physics and cosmology do not presuppose the conclusions of other disciplines - as does biology relying on chemistry and physics, and chemistry relying on physics. When we step back from physics and cosmology to

10. William STOEgER, "Contemporary Cosmology and its Implications for the Science-Religion Dialogue" in Robert J. RuSSELL, William STOEGER, SJ, and George CoYNe, eds., Physics, Philosophy and Theology: A Common Quest for Understanding, Vatican City, Vatican Observatory Publications, 1988, p. 226.

11. Ibid., p.184 
justify the assumptions and presuppositions we employ in pursuing them, we have nowhere to go, except to some sort of philosophical reflection ${ }^{12}$."

This reflection upon universal realities is made "from the standpoint of how they are given to us as knowers [...] and of the role they play in the general structures of knowing and of being as we know it..."It is important to underline that a generalized knowing is not unique to scientific explanation, not even to cosmology as an ultimate science: "This pervasive and general structuring to which philosophy is attentive is fundamentally pre-scientific...it is based on experience ${ }^{13}$." Therefore, when philosophical questions arise from cosmological study, there is a further realization:

"cosmology is also pervasive - but pervasive, so to speak, in its object, not in our experience or knowledge of the object. In philosophy, both the object and our experience of it are pervasive or general. Thus philosophy attends to the intelligible wholes and structures, and to their interrelations, which must be assumed or presupposed by the sciences ${ }^{14}$."

Cosmology and philosophical reflection are deeply connected along a subject/object distinction, thus demonstrating cosmology's unique role in uncovering foundational demarcations in human knowledge. Stoeger's argument for the pervasiveness of cosmology in the face of our "subjective" appraisal of this pervasiveness nicely explicates what Munitz claims in his distinction between the empirical and the existential reasons for undertaking cosmology. At root therefore, there is not a radical separation between scientific cosmology and the effort to derive meaning from such a unified discipline.

The interaction between these disciplines is heuristic. It is an interdisciplinary integration in inquiry, not a straight metaphysical account of what knowledge exists in cosmology. It centers on the role played by rationality, and what we intend as knowers. The terms for pursuing this option are as much epistemological as they are metaphysical or theological. Without a settling of the epistemological questions, cosmology's significance for theology will remain a problem.

12. Ibid., p.227

13. Ibid., p.226

14. Ibid. 
The affirmation of knowledge in scientific cosmology is philosophically significant because philosophy points out what judgments or implications result. Philosophy takes up the questions about the character of cosmological knowledge that cannot be answered by cosmology itself. Cosmology highlights the limits of what science qua science can investigate. Philosophy arises out of this empirical set of inquiries, and it determines how the limits of those inquiries are exhausted. It then aims further to account for other knowledge that arises out of this empirically defined understanding of inquiry in a single universe.

So, philosophy poses a challenge to cosmology in the form of an inquiry into ultimate inquiry. The creative unfolding of questions exhibits a telos in inquiry. This means, first of all, that this telos is not necessarily observable in the universe. Frequently, in New Age thought, which is set out in contexts distant from the practice of science and philosophy of science, the "directionality" of the universe is conceived in naïve realist terms, as something that can be merely perceived rather than judged. On the contrary, the order that is suggested by this notion of teleology overturns such common sense approaches. There is no way to sidestep the critical interface between cosmology and philosophy. By focussing on the success of inquiry, this strategy also undercuts to a certain extent the terms of the debate between advocates of chaos and order. Some of the best known writers and thinkers in this debate are Steven Weinberg and Richard Dawkins, who advocate cosmic indifference. On the other hand, John Polkinghorne, Nancey Murphy, Robert Russell and George Ellis argue for a divine ordering of the universe based on certain features of nature that appear orderly or fundamentally open ${ }^{15}$. I prefer to understand telos from an admittedly more anthropocentric viewpoint, in a discipline-centered approach. The data by themselves do not convey a sense of purpose unless taken together with the fact that they are cumulatively intelligible through human inquiry. Human inquiry is the leading edge of a teleological direction of the universe by pointing selfreflexively. We advert to the limits of the empirical sciences in cosmology and the implications of this limit reflect a broader notion of interiority as self-transcendence. In short, self-transcendence is the significance of

15. See the contributions of the advocates of cosmic order in RUSSELL, Stoeger, Coyne, eds., Physics, Philosophy and Theology: A Common Quest for Understanding, Vatican City, Vatican Observatory Publications, 1988. 
cosmology and its limits as a source of knowledge about the directionality of intelligence in an intelligible universe.

\section{Self-Transcendence and Scientific Method: McMullin's Theory of Retroduction}

The well-established rigour of scientific method has enriched cosmological reflection. Theory and experiment interact in cosmology in a way that is not dissimilar to other scientific disciplines. However, it takes theoretical physics to a philosophical threshold that distinguishes it from the other natural sciences. But is there a theory of science that might account for this trajectory? In short, if cosmology is not anchored in a theory of scientific practice, it may be perceived as offering an ideal of science, even as a possible theological projection of an idea of unified science without sufficient empirical reference.

This is precisely the problem that is addressed in the work of Ernan McMullin through his theory of scientific rationality. He terms this theory retroduction, which accounts for both inductive and deductive inferences about natural process as a philosophy of the history of science. In part, it is a comprehensive realist response to the work of Thomas Kuhn and the various schools of historicism and social construction that have built up around Kuhn's landmark work The Structure of Scientific Revolutions (Chicago, Univ. of Chicago Press, 1962, 1970). Retroduction affirms the imaginative capacities of human inquiry that operate on both observable and non-observable entities. His theory points to the unique role of scientific theories in mediating scientific explanation with a variety of historical contingencies that shape science's social dimensions. Scientific theories, once marshalled in a successful process of verification, are realist in their intent and historically subjective in their progressive, probabilistic formulations ${ }^{16}$. Its applicability to cosmology, a science and form of philosophy, could not be more evident. McMullin's strategy affirms what cosmology investi-

16. For more detail on Mc MuLLIN's thought on scientific rationality, see "History and philosophy of science: a taxonomy" in R. STUEWER, ed. Historical and Philosophical Perspectives of Science Minneapolis, University Press, 1970, p. 12-67; "Capacities and natures: an Exercise in Ontology" in Boston Studies 11, 1971, p. 63-82; "A Case for Scientific Realism" in J. LEPLIN, ed. Scientific Realism, Berkeley, University of California Press, 1984, 
gates in its inherently theoretical structure. The universe is progressively grasped as an object of human inquiry apart from direct or indirect theological implications that may arise at any point along the way.

One of McMullin's first published articles in 1955 is entitled "Realism in Modern Cosmology," a taxonomy of early twentieth century approaches which comes to terms with what was then recent spectroscopically aided observations of a large-scale universe ${ }^{17}$. In this article, McMullin outlines a philosophy of nature in terms of a 'qualified realism.' McMullin qualifies his realism because demonstratively certain knowledge of the physical world deduced from causes to effects is not viable. In often cited article written in 1981, McMullin revisits the question of philosophy and cosmology with the added insights of his historical studies undertaken in the intervening 25 years, having formulated the theory of retroduction during that time ${ }^{18}$. Echoing Munitz, McMullin states that science becomes philosophy "at its most innovative point" and scientific cosmology's question of the unity of the universe is clearly "an interesting one" because the sciences' inability to answer these questions is not a form of agnosticism about the universe's character. Rather, admitting their philosophical character is to "recall that science itself cannot answer them without begging the question ${ }^{19}$."

p. 8-40; "The goals of natural science", American Philosophical Association presidential Address in Proceedings of the American Philosophical Association 58, 1984, p. 37-64; "Explanatory success and the truth of theory" in RESCHER, NICHOLAS, ed. Scientific Inquiry in Philosophical Perspective, New York, University Press of America, 1987, p. 51-73; "The shaping of scientific rationality" in Ernan Mc MulliN, ed. Construction and Constraint: The Shaping of Scientific Rationality, Notre Dame, University of Notre Dame Press, 1988, p. 1-47; The Inference that Makes Science (Aquinas Lecture) Milwaukee, Marquette University Press, 1992, "Enlarging Imagination" in Tijdschrift voor Filosofie 58, n.2 (June, 1996), p. 227-260.

17. "Realism in Modern Cosmology" in Proceedings, American Catholic Philosophy Association 29, 1955, p. 137- 50.

18. How should cosmology relate to theology?" in Arthur PEACOCKE, ed. The Sciences and Theology in the Twentieth Century, Notre Dame, IN, University of Notre Dame Press, 1981, p. 17-57.

19. Mc Mullin, "Is Philosophy Relevant to Cosmology?" in American Philosophical Quarterly 18, 1981, p. 181 
The scientific enterprise is not diminished by this limitation, but rather extended into the philosophy of science, conceived as a constructive, positive sub-discipline:

"[...] the fascination of cosmology for the philosopher is in part due to this; it is as much a testing-ground for the philosopher's theories of science as it is for the physicist's theories of matter ${ }^{20}$."

Cosmology's inherent philosophical structure reveals a cross-traffic between the disciplines that resembles the hazy relationship between mathematics and logic, where logic is involved in the act of clarification. This task of clarification is itself significant. The importance of philosophical clarification, moreover, is made concrete in terms of sorting through conceptual presuppositions, implications, consistency and frameworks. As science becomes more innovative, as it approaches a revolutionary stage according to Thomas Kuhn's terminology, the anticipation of radical theory-change involves appraising the conceptual issues that twentieth-century science has shown to be so crucial ${ }^{21}$.

Indeed, cosmology as a discipline exudes a tremendous amount of conceptual elasticity, and as a domain with such a broad philosophical appeal in this respect alone, it is clear why it possesses so much capacity for identifying a mediation between empirical intelligibility and abstract theorizing, which is the entrance point for existential questions. From the point of view of articulating a unified epistemological view, what is significant is McMullin's suggestive claim that

"retroduction can...establish the existence of structures and processes altogether different from any that lie within direct reach, and is limited only by the resources of the scientific imagination...It is on this much more powerful pattern of inference that cosmology mainly relies ${ }^{22}$."

Retroduction, as an account of scientific rationality in cosmology, is the key tool that reveals a startling symmetry. This symmetry is the degree to which the most general theories of mechanics can provide coherent explanations of known cosmological data. As the recent Hubble telescope observations of the last ten years shows, these theo-

20. Ibid.

21. Ibid.

22. Ibid., p. 180. 
ries are verified as successful in the accumulation of further empirical evidence $^{23}$.

What does this stress on McMullin's theory of retroduction in cosmology mean? In short, it leads to affirming an epistemologically realist position concerning the universe as a single unified object:

"When the spectra of distant stars, or the velocities of distant galaxies, continue to be interpretable by schemas derived from terrestrial processes, confidence quite properly grows in the assumption that these schemas are not just conventions imposed for convention's sake or because our minds cannot operate otherwise, but that all parts of the universe are united in a web of physical process which is accessible through coherent and ever-widening theoretical constructs created and continually modified by us ${ }^{24}$."

The universe discloses itself through theory, creative imagination and eventual verification that together constitute progress in the growth of knowledge. To repeat, a dialectical (subject/object) conception of cosmological knowledge is overcome by the sheer confidence in the modified and modifiable sets of theoretical constructs that germinate out from the extant body of interpretative schemas operative in terrestrially restricted sciences. The form of the disclosure of the universe is congruent with the peculiar imaginative schemes of theories and concepts that must await empirical verification, yet they remain valid heuristic tools that operate on occasionally simultaneous fronts to illuminate aspects of parallel investigations. The irreducibility of purposeful human subjectivity and cosmic intelligibility are confirmed through sets of operations in inquiry.

The affirmation of realism in cosmology through retroductive inference raises the issue of the anthropic principle. First introduced

23. This point was highlighted for me by Prof. Edmund Bertschinger (Astrophysics, MIT) in a personal conversation in January, 1999. Bertschinger highlighted the evolution of cosmology over the past decade as a history of successful observations supporting a range of previously theoretical hypotheses. Cosmology is therefore not only intelligible in terms of a predictive capacity of certain good theories over others. It is, over time, empirically justified as well. The January, 1999 issue of Scientific American details some of these recent successes.

24. Mc Mullin, "Is Philosophy Relevant to Cosmology?”, p. 181. 
by Collins and Hawking ${ }^{25}$, coined by Brandon Carter ${ }^{26}$, and interpreted by Barrow and Tipler ${ }^{27}$, the anthropic principle now serves a peculiar central role in identifying the cosmic status of human beings. It purports to provide an explanatory account for human existence due to the evidence of the delicate balance of energy and initial forces as conditions for a habitable universe to emerge. The implications of this explanatory account provide possible grounds for a new "teleological argument" for the existence of God.

Judging by McMullin's strong arguments to defend the role of human creative genius in accounting for the real, it would be natural to assume that he would sympathize with the effort to grant significance to the anthropic principle. The assumption would be that the natural sciences have collaborated to uncover a key cosmological "meta-constant" illuminating cosmology in a way that puts the human mind at the centre of the universe by giving it purpose. But, in comparison with other philosophers and theologians who exhibit such enthusiasm for the anthropic principle, McMullin's reflections are cautious and circumspect.

McMullin does not cede explanatory possibility to the anthropic principle, due to his identification of the clear lessons to be drawn from historical antecedents of the anthropic principle, and the credibility with which alternative explanations might enjoy. These other interpretations of the anthropic principle are summed up by McMullin as comprising an 'indifference principle.'

The indifference principle is a contender to the anthropic principle. The indifference principle can be put in the following terms: "whatever theory we propose for the early universe, it ought to be indifferent to (independent of) any particular initial conditions ${ }^{28}$." In

25. See C.B. Collins and S. W. HawkING, "Why is the Universe Isotropic?" in Astrophysical Journal 180 (1973), p. 317-334.

26. Brandon CARTER, "Large Number Coincidences and anthropic principle in cosmology" in M.A. LONGAIR, ed. Confrontation of Cosmological Theories with Observational Data, Dordrecht, 1974, p. 291-298.

27. John Barrow and F.J Tipler, The Anthropic Cosmological Principle, Oxford, Clarendon Press, 1986

28. See Mc Mullin's discussion of the indifference principle in "Long ago and far away: Cosmology as extrapolation" in R. Fuller, ed. Bang: the Evolving Cosmos, Lanham, MD., University Press of America, 1994, p.135. 
spite of the fact that Collins and Hawking identified a significance to the discrete value of the initial energy field, manifest in the state of space-time $10^{30}$ seconds after the Big bang, Alan Guth has re-formulated the Big Bang hypothesis according to an 'inflationary hypothesis.' This hypothesis proposes a radical plurality of universes, as the result of the inflation of an atom at the extremely early time of $10^{-50}$ seconds after the singularity. This would be responsible for the virtually disconnected causal connections between universes ${ }^{29}$. In effect, this contender critically de-stabilizes the anthropic principle. With such a plurality of universes, the significance of an anthropic universe dwindles. The existential implications of this substantial modification of the Big Bang theory are tangible. One of these implications is that the argument for the "fine-tuning of the initial energy-density [would become] unnecessary ${ }^{30}$."

McMullin treats the issue of the anthropic principle in terms of its' merits and demerits as a scientific theory in light of the kind of challenges from plausible alternatives like the 'indifference principle.' As a theory that requires measuring against the other options, the anthropic principle requires a thorough examination. One of the key theological links is with the Big Bang theory itself. It has only recently emerged as the victorious theory over the Steady State theory of Bondi, Gold and Hoyle. This cosmological breakthrough was made possible by the discovery by Penzias and Wilson in the 1960's of the cosmic microwave background radiation that courses through the observable universe at 3EK. This was clarified by Collins and Hawking's calculation from which they concluded that the likelihood of the emergence of this universe is extremely unlikely under almost any other arbitrary initial conditions. From this calculation emerged the anthropic principle due to the extraordinary flatness of the initial mass-density of the universe along a razor edge between runaway expansion and rapid collapse.

McMullin cites how Collins and Hawking drew famous conclusions from their results: "The fact that we have observed the universe to be isotropic is therefore only a consequence of our own exis-

29. This theory has some support from other cosmologists including Lee Smolin, David Deutsch, Martin Rees and John Gribbin.

30. Mc Muluin, “Long Ago and Far Away", 1994, p.138. 
tence ${ }^{31}$." The circular reasoning that the anthropic principle implies appears tautologous. McMullin thus retains his focus on the logic involved by asking: "...surely a necessary condition cannot function as an explanation 32 ?"

In analysing the anthropic principle as it grew directly out of these discussions, McMullin elaborates on a distinction that is made elsewhere between the weak and strong versions. He criticizes the misleading way in which the word 'principle' is used. In its weak forms, the anthropic principle appears to be either trivial or at least as restrictive as the earlier dominant 'Copernican principle'. What about the Strong Anthropic Principle? In beginning with Carter's formulation of it in 1974, it is meant to explain a necessary character to human existence derived from an interpretation of the restrictions on physical constants arising from coincidences in energy and mass levels in the universe. But, what is held to be explanatory can easily collapse as a meaningless statement:

"the appearance within this ensemble of coexistent universes of one capable of bearing life might be regarded as (more or less) necessary [...] Because among all the (actual) universes featuring different constants, we (of course) will be found in one that permits our existence ${ }^{33}$."

But do "the many universes have to exist? Surely not." says McMullin ${ }^{34}$. He shifts the focus in order to address more directly the kind of cosmic and philosophic knowledge that these anthropic principles are seeking to identify. If the strong version of the principle can be reformulated in terms of evidence of 'cosmic fine-tuning,' what do anthropic types of explanation actually explain?

Two options are available, according to McMullin, as true explanations of cosmic natural process. Either we opt to view this universe as simply the way it is due to its being insignificant in light of the plethora of other possible universes ${ }^{35}$. Or, the alternative is to ask

31. Cited in "Indifference principle and anthropic principle in cosmology" in Studies in the History and Philosophy of Science 24, 1993, p.371. Cf. Collins and Hawking, 1973, p. 319.

32. Mc MulLin, 1993, p. 371.

33. Mc MulLin, 1993, p. 371.

34. Ibid., p. 377.

35. Ibid., p. 379. 
whether a universe of this kind has a special significance in terms of some system of meaning, one that would suggest a likely explanation of the apparent parameter condition. Such an "explanation" would definitely be preferred instead of leaving the universe as mere coincidence.

In pushing the questions further in light of the creative desire for explanation, McMullin finds the question of intelligibility exhausted. But, resources from what he terms "systems of meaning" might potentially answer the question. In pushing inquiry forward, not only is philosophy per se being invoked, it is being evoked in such a way to counter the kind of thinking suggested by Carl Sagan's quote that introduced this paper. "Systems of meaning" implicates theology and religious meaning. At this point, it is essential to recognize the indirect and non-linear way in which a theological 'explanation' is introduced as the "cause" of the cosmological effect. The cosmic effect is known as the terms and relations of the universe's initial or boundary conditions that are the explanandum requiring an explanans.

By speaking of "systems of meaning," McMullin is avoiding the inherent difficulties of closely associating the anthropic principle with a divinely ordered universe. The route that McMullin employs to articulate a God-World relationship, in light of the problems raised by the anthropic principle, is nevertheless an "anthropic" route of inquiry. The recourse to "systems of meaning", as an alternative strategy accounting for the existence of initial conditions only comes on the heels of a meticulous procedure of laying out the series of problems and their interrelationships arising from a consideration of the anthropic principle. It is impossible to view systems of meaning as something separate from religious, mythical, social or psychological fields of inquiry, to which meaning is more commonly attached as something that is intelligible and investigated.

McMullin's approach to the anthropic principle is articulated succinctly in a more recent article, "Indifference Principle and Anthropic Principle in Cosmology ${ }^{36}$." One point in particular stands out from this article, because of the way McMullin broadens the range of implied questions raised by the anthropic principle. It is the distinc-

36. "Indifference principle and anthropic principle in cosmology" in Studies in the History and Philosophy of Science 24, 1993, p. 359-89. 
tion between the empirical and the metaphysical, a distinction between explanatory knowledge of unobserved causes and the acts of interpretation such knowledge allows. The importance of this distinction for cosmology is more apparent now than ever:

“Modern cosmology has been...directed by 'principles' whose credentials are remarkably difficult to assess. The degree of conceptual extrapolation is so extreme and the possibilities of empirical test are so slender that cosmologists often have to rely on the most elusive of intuitions...These intuitions derive from...sources that in many cases lie outside the confines of 'normal' science. This is why the boundaries between cosmology and metaphysics or even theology seem so permeable ${ }^{37}$."

The critical point is that the theological impulse to interpret the anthropic principle is not an intrusive metaphysical dimension to contemporary cosmology. As McMullin points out,

"The fierceness of the commitment of some to the indifference principle and the openness of others to unorthodox anthropic hypotheses reflect broader metaphysical commitments ${ }^{38}$."

The problems that cosmology and the anthropic principle pose are therefore problems not about which metaphysical interpretation is the most theologically adequate. Retroduction, as a theory of science, shows that values and imagination already operate meta-physically in the process of scientific explanation. The question becomes one of how a metaphysical commitment best coheres with the particular stages of inquiry in cosmological investigations.

The anthropic principle is inherently vulnerable, as an interpretable theory of data. The anthropic principle derives

"from the claim (1) that the most basic structures of the universe might have been different from what they are; and (2) that the development of rational life in the universe depends on their being more or less exactly what they, in fact, are ${ }^{39}$."

McMullin seems to have no problem, however, with deriving meaning from the anthropic principle if it is clear that another form of explanation drawing on meaning itself is taken into consideration:

37. Mc Mullin, 1993, p. 387.

38. Ibid..

39. Mc Mullin, “Is Philosophy Relevant to Cosmology?”, 1981, p.186. 
"If the universe is the work of a Creator... Reasons can be given in the traditional Judaeo-Christian perspective, why God would want man in the world. Thus, the explanation is not merely by the presumed fact of choice, but by some presumptive reasons for the choice. The anthropic principle, if fortified by the traditional doctrine of creation, does therefore give an explanation, though it is no longer, of course, a scientific explanation ${ }^{40}$."

The anthropic example is an example of how cosmological theory in general directs itself, almost autonomously, into the philosophical domain:

"Cosmology of its very nature demands extrapolation, often quite daring extrapolation. Because its objects are distant and unfamiliar, it has always had to rely on indirect and precarious modes of reasoning ${ }^{41}$."

Through extrapolation, cosmology goes beyond the bounds of empirical observation to attempt the verification of theories such as the anthropic principle. As McMullin shows with respect to the Aristotelian legacy of cosmological philosophy of science, the act of extrapolation is a natural extension of empirical inquiry. It should not be understood in opposition to deduction or induction, seen as the proper method for science. Rather, the act of extrapolation defies a demonstrative or positivist ideal in the philosophy of science. But since cosmological theories are often verified as "fertile" in congruent relation with one another, the act of extrapolation also defies a strictly historicist or relativist reading in the philosophy of science. The result is a portrait of free human inquiry that achieves real metaphysical knowledge, contingent on progressive, empirical results.

\section{Theology and Self-Transcendence}

Although empirically based, the mediating role of theory in cosmology is so extraordinary, and the urgency of the questions so clear, that the move to incorporate systems of meaning (i.e.: creation) into a meta-explanatory framework is not a reversion to "mere" interpretation. The fact that cosmology makes demands on the human imagination in a dynamic way, positively begs for the systems of meaning to emerge in order to supply an understanding of the universe. On this

40. Ibid.

41. Mc Mullin, "Long Ago and Far Away”, p.113. 
account, however, the understanding is one of creation, a theological category. Where the terms and relations of meaning will fit depends on what can be developed metaphysically. An explicit metaphysical approach must await further advances however. As McMullin comments,

"The problem in the end is one of metaphilosophy, of deciding on the sort of warrant that is appropriate to philosophic and to scientific claims, seen not as two entirely different sorts of intellectual pursuit, but as a continuum. What has made the issue more intractable is the pace of development of theoretical cosmology, a pace too rapid of late to allow metaphilosophy the time it needs to take stock ${ }^{42}$."

The significance and precise role of a meta-philosophy should be carefully noted. With the historical verification of explanation in the sciences aided by the human imagination, such a metaphilosophy called for by McMullin may be closer at hand than he realizes. In the context of his theory of rationality, McMullin's reflections in cosmology pose as potent suggestions.

As stated earlier, the reason for highlighting cosmology is because we need to assess scientific rationality at its philosophical limits. As hinted earlier, one way of accounting for the meta-philosophy that is still required is to follow Lonergan's proposal of emergent probability. This worldview holds great promise for allowing both an inquiry into rationality and the inquiries of various scientific disciplines to interrelate. While there is not space in this article to pursue emergent probability further, it suggests a metaphysical verification of the cosmology/philosophy/theology integration. The significance of cosmology lies in simply indicating that a surplus of meaning exists at the limit of scientific inquiry. A philosophical metaphysic for the sciencetheology dialogue cannot separate an understanding of cosmology from an epistemological account of empirical and existential dimensions of rationality.

It is true that cosmology can mediate the science-theology dialogue. However, the mediation is implied at the scientific starting point from which the operations of consciousness are self-reflectively dedicated to understanding the connections that draw the scientific ques-

42. Mc MulLin, "Is Philosophy Relevant to Cosmology?”, 1981, p.189. 
tions into philosophical and eventually theological questions. Cosmology is not implied in its tentative theoretical data or its conclusions. What is clear is that the range of questions and reflections along a transcendent trajectory from within the heart of scientific inquiry extend to encompass other distinct operations of human reflection. Cosmology shows how empirically relevant are these elements of meaning, because they already arise out of the exigencies of creativity and imagination at work in the formulation and verification of scientific theories.

Cosmology does not necessitate additional reflections on the structure of interiority in terms of human creativity or religious desire. Neither does cosmology necessitate the spiritual horizon illuminated by theology and religious reflections. However, it does imply a positive spiritually originating heuristic to scientific rationality. It points to something beyond what is simultaneously scientific and rational. It points to further questions for interpretation, to which answers are given outside the sphere of science. These questions and answers nevertheless stand in need of some kind of structured relationship beyond a mere affirmation of interiority. This is the indirect way in which the discipline of theology is linked to cosmology.

Scientific cosmology has blossomed at a peculiar moment in the history of Christian theology. A split that opened up in the nineteenth century between theological styles that were either receptive or hostile to the modern world has widened. On the one hand, there are the public theologies: the liberal, contextual, hermeneutical, liberationist, feminist, ecological and other forms of theological expression that are correlationist. This style of theology seeks to correlate different patterns of human experience and history with generalized religious patterns of living and expression. The names chiefly associated with this style are Schleiermacher, Tillich, Bultmann, Küng and David Tracy to name a few. For the correlationists, culture is normative yet historically dynamic.

The second style of Christian theology, which continues to thrive, is a more strictly spiritual theology. It tends to be a doctrinal or systematic style of theology. Frequently, it is ecclesial, liturgical, textually intra-hermeneutical, iconic, mystical and inwardly directed. In this style, culture plays a supporting role in reflecting and representing particular spiritual and theological identities. These identities provide 
privileged symbolic, affectively construed access to the spiritual life, which is a distinct form of drama. The names associated with this style of theology include Barth, von Balthasar, Niebuhr and more recently, the non-foundationalists such as Hans Frei, George Lindbeck and John Milbank. While public theology stresses culture and its spiritual component, spiritual theology focusses on the spiritual life with its culturally formed extensions. Increasingly these two styles of theology employ different methods that cut across other traditional theological demarcations, such as denominational tradition.

So, how might cosmology concern itself with this situation of theological division? At first glance, it might appear to fit with a public/correlationist theology in broadening religious meaning. But, there seems to be more to it than this. The findings of cosmology over the last 50 years raise philosophical issues so fundamental that they put the basic Enlightenment separation of scientific rationality and existential rationality into serious question. The reason is that both forms of rationality exhibit positive signs of self-transcendence. Cosmology is where they poignantly intersect. In science, self-transcendence is the fruit of empirical inquiry provided that the inquirer is fully aware of the kind of inquiry that has been made. Existential selftranscendence is most generally verified through the appreciation of contemporary cosmology. Self-transcendence is what Lonergan calls an isomorphism between person and universe, between subject in act and object as understood. In traditional philosophy, this kind of claim has been defended with reference to the idea of "correspondence ${ }^{43}$." The result for theology is that cosmological discourse hints of God in

43. Jean Ladrière notes that correspondence is what finally lies behind the various concepts of truth. The problem, according to Ladrière, becomes one of how this correspondence is ascertained in different fields. In a remark that resembles McMullin's theory of retroduction, he comments that in science, this problem of correspondence is addressed in theory assessment. In theology, this problem is addressed in the degree of faithfulness that theological statements show toward original religious texts and religious experience. See Jean LADRIÈRE, "The Role of Philosophy in the ScienceTheology Dialogue" in Studies in Science and Theology: the interplay between scientific and theological worldviews, Genève, Labor et Fides, 1999, p. 217-237, especially p. 229. 
a way that would lead us to think more seriously about adopting a common method with a focus on self-transcendence.

In summary, contemporary cosmology functions in a dialogue with Christian theology as a discipline in which theologians can learn new, authentic markers of spirituality and interiority, markers that are foreshadowed in science and made real in self-transcendence. Cosmology illumines the God question by working in and explicitly acknowledging the transcending structure of human inquiry and the ultimate meaning of that inquiry. In so doing, it asks philosophical questions that in turn give rise to theological questions. It demands that theologians pay attention to how interdisciplinary correlation and spiritually oriented reflection fit together. Cosmology, with its wondrous attention to the latest understandings of the universe, resituates theology in terms of the human subject's quest for purpose and destiny, but in the way that most contemporary theologians could not imagine until recently.

\section{RÉSUMÉ}

Dans cet article, je suggère que la signification première de la cosmologie pour la théologie passe par la notion d'auto-transcendance. C'est une notion foncièrement théologique qui émerge dans la cosmologie. Elle pointe vers le domaine de l'intériorité mis de l'avant par la théologie contemporaine. A partir, en particulier, de la pensée d'Ernan McMullin, j'affirme que l'auto-transcendance émerge d'une recherche cosmologique quand elle devient philosophie et comporte une extrapolation. Une ouverture théologique envers la cosmologie est justifiée quand on en saisit les limites en tant que discipline empirique au cœur des questions existentielles possibles sur le sens de l'univers ; un déplacement qui est bien illustré par le principe anthropique.

\section{ABTRACT}

In this article, I argue that the primary significance of cosmology for theology is through a notion of self-transcendence. It is an inherently theological notion arising within cosmology. It points to the realm of interiority claimed by contemporary theology. Employing the thought of Ernan McMullin in particular, I claim that self-transcendence emerges within cosmological inquiry when it becomes philosophy, and when extrapolation is involved. A theological thrust to cosmology is confirmed when one understands the limits of cosmology as an empirical discipline amidst the existential questions that can be posed about the meaning of the universe, a development well illustrated by the anthropic principle. 